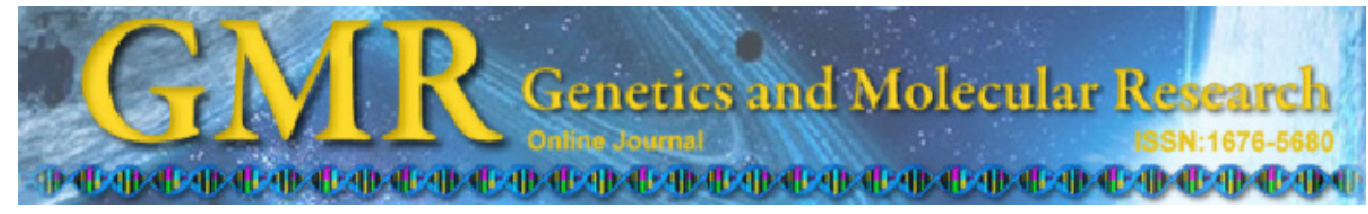

\title{
Evaluation of genetic dissimilarity in a segregating wine grape population
}

\author{
A.P. Viana ${ }^{1}$, S. Riaz $^{2}$ and M.A. Walker \\ ${ }^{1}$ Laboratório de Melhoramento Genético Vegetal, \\ Universidade Estadual do Norte Fluminense Darcy Ribeiro, \\ Campos dos Goytacazes, RJ, Brasil \\ ${ }^{2}$ Department of Viticulture \& Enology, University of California, \\ Davis, CA, USA \\ Corresponding author: A.P. Viana \\ E-mail: pirapora@uenf.br
}

Genet. Mol. Res. 10 (4): 3847-3855 (2011)

Received June 6, 2011

Accepted October 7, 2011

Published November 8, 2011

DOI http://dx.doi.org/10.4238/2011.November.8.6

\begin{abstract}
This study examined the genetic diversity present in a population obtained by crossing two very distinctive varieties of wine grapes (142 progeny from a Riesling x Cabernet Sauvignon cross, including both parents, created at the University of California). The following list of morphological characters were evaluated and found to segregate in this population: cluster weight, cluster length, presence or absence of cluster wings, cluster wing length, number of berries, cluster density (CD), and berry weight. The following juice parameters were also measured: ${ }^{\circ} \mathrm{Brix}, \mathrm{pH}$, total phenolics, and titratable acidity. Genetic diversity within this population was estimated through multivariate methods that utilized the Gower index of dissimilarity and UPGMA clustering. The correlations between traits and relative contribution of each variable were also compared. Eleven groups of progeny were distinguished into categories with low, intermediate and high values for cluster weight and cluster density, and low and high values for total phenolics. An inverse correlation was detected between the variables related to production and those related to the quality of the fruit. Principal components analysis demonstrated that all variables examined in this study are important for the correct discrimination of optimal
\end{abstract}


genotypes in this population. These statistical tools can be used to select individuals with the greatest potential for producing high-quality wines.

Key words: Grape breeding; Principal components analysis; Fruit quality; Multivariate analysis

\section{INTRODUCTION}

High-quality wine is a product of the environment in which the grapevines are grown, grower practices to enhance fruit quality, and the correct choice of varieties for a given environment. The choice of variety is based on traits related to yield and fruit quality such as cluster size and density, fruitfulness and berry size, sugar levels, acidity and total phenolics. Cluster compactness is of key importance because of the association of compact clusters with bunch rot due to Botrytis cinerea and other cluster rot organisms (Vail and Marois, 1991; Marois et al., 1992). Compressed berries in a compact cluster have altered epicuticular wax development, which in combination with decreased air movement and evaporation of free water within compact clusters increases the likelihood of fungal attack (Marois et al., 1986). Research on other crops such as pistachio and castor beans also supports the positive relationship of susceptibility to botrytis and compact nature of the fruiting body (Thomas and Orellana, 1963; Michailides, 1991).

Cluster compactness can be modified with a pre-bloom application of gibberellic acid, which results in reduced fruit set, looser clusters and lower rot levels (Weaver et al., 1962). Winemakers also prefer small berries particularly in red wine grape varieties because the higher ratio of skin to pulp can be associated with increased color intensity in the wine. However, there are no detailed analyses of the genetic and environmental components that affect cluster architecture. In addition, next year's clusters are initiated while this year's clusters are flowering. Light and temperature influence the number of clusters during the previous season, and cluster size and berry set during the current season. Nonetheless, identifying genomic regions that control cluster compactness in breeding populations segregating for this trait would be an important step forward in understanding the underlying genetics controlling cluster architecture.

The essential foundation of any breeding program is a germplasm pool that represents a wide range of genetic diversity and is capable of producing segregating hybrid populations from which novel phenotypes can be selected (Riseberg and Ellstrand, 1993). The generation of extreme hybrid phenotypes (i.e., phenotypes with characteristics that exceed those of either parental line) is referred to as transgressive segregation (deVicent and Tanksley, 1993). Transgressive segregation is a mechanism for rapid evolutionary change because hybridization generates variation at many genes simultaneously and the variant alleles have already been tested by selection. The amount of genetic variability in a segregating population depends upon the genetic differences between the parents (Falconer and Mackay, 1996). This parental diversity can be estimated by predictive multivariate techniques such as principal components analysis, canonical variables and other clustering methods. The choice of the method depends on the precision the breeder desires, as well as their ability to analyze and acquire data (Cruz and Carneiro, 2003).

The study presented here examined the genetic diversity in a population of wine grape genotypes obtained from a cross of two important wine grape varieties, Riesling x Cabernet Sauvignon. The goal of this study was to identify superior genotypes that could be used in a regional grape improvement program. 


\section{MATERIAL AND METHODS}

\section{Plant material}

The study examined 142 progeny from a Riesling x Cabernet Sauvignon cross (including both parents) created at the University of California, Davis. The parents were chosen because they differed significantly in fruit morphology, flavor and aromas. The cross was made in 1994 and the resulting progeny (one plant of each genotype) was planted in the field in 1995. The majority of the progeny fruited for the first time in 1997. This population is now planted at the National Clonal Germplasm Repository, in Winters, California

\section{Traits measured}

\section{Cluster morphology traits}

Four to five clusters were randomly harvested from each plant in the population during the first week of September 2009. Three clusters were evaluated individually for the following traits: total cluster (including all laterals, wings and the peduncle) weight in grams $(\mathrm{CW})$, cluster length in $\mathrm{cm}(\mathrm{CL})$, berry weight in $\mathrm{g}(\mathrm{BW})$, number of berries $(\mathrm{BN})$, presence or absence of a wing (W), wing weight in $\mathrm{g}(\mathrm{WW})$, wing length in $\mathrm{cm}$ (WL), cluster density (CD), ${ }^{\circ}$ Brix, $\mathrm{pH}$, total phenolics in $\mathrm{mg} / \mathrm{cm}^{2}$ of the skin (TP), and titratable acidity (TA). In addition the number of clusters for each plant was counted $(\mathrm{CN})$. Cluster density was recorded by ranking the clusters from 1 (very loose) to 9 (very dense, berry shape deformed) based on the classes described in Descriptors for Grapevine Vitis spp. (IPGRI et al., 1997).

\section{Fruit composition traits}

Berries from each of the three clusters harvested per genotype were placed in cheesecloth and juiced in a standard hand press. Juice was kept in refrigerator overnight to sediment solids, and the next day clarified juice was transferred into new tubes and kept in $-20^{\circ} \mathrm{C}$ to prevent fermentation. Using the clarified juice, total soluble solids ( ${ }^{\circ}$ Brix) were measured with a calibrated refractometer (model N1; Atago, Tokyo, Japan). Titratable acidity (TA) was measured by $\mathrm{NaOH}$-based titration expressed as grams of tartaric acid in 1,000 $\mathrm{mL}$ of juice. The $\mathrm{pH}$ of the juice was determined using a calibrated $\mathrm{pH}$ meter. Three independent readings for each trait were taken and their average was used.

Total phenolic concentration was determined using skin discs (4 $\mathrm{mm}$ in diameter) that were removed from the equator of 15 frozen berries for each sample. The discs were placed in polystyrene tubes containing $30 \mathrm{~mL}$ of acidified methanol $(1 \% \mathrm{HCl} \mathrm{v} / \mathrm{v})$ and extracted in the dark. After $48 \mathrm{~h}$, samples were mixed and allowed to settle. Absorbance was determined at 440 $\mathrm{nm}$, and total phenolic concentration was expressed as $\mathrm{mg}$ gallic acid equivalents (GAE) $/ \mathrm{cm}^{2}$ berry skin (Amerine and Ough, 1980; Dokoozlian and Kliewer, 1996).

\section{Statistical analyses}

Descriptive statistics for each variable were calculated by estimating the average, 
minimum and maximum values, coefficient of variation, variance, standard deviation and confidence interval for the upper and lower limits at $95 \%$ probability. The Gower dissimilarity index (Gower, 1971) and UPGMA dendrogram of genetic dissimilarities were used to analyze the genetic diversity and to estimate genetic distances between genotypes. The Gower dissimilarity index was used because the study's set of variables formed a mixed group; quantitative and binary (in case of presence or absence of wing) variables. The Gower index utilizes both qualitative and quantitative data to generate a single index of dissimilarity ranging from 0 to 1. Dissimilarity was given by:

$$
S i j=\frac{\sum_{k=1}^{p} W_{i j k} \cdot S_{i j k}}{\sum_{K=1}^{p} W_{i j k}}
$$

with $\mathrm{i}$ and $\mathrm{j}$ representing the individuals to be compared with respect to the characteristic $\mathrm{k} ; p=$ total number of features, and $S_{i j}=$ the contribution of variable $\mathrm{k}$ for the total distance. If a variable is qualitative, $S_{i j k}$ takes the value 1 when agreement is positive or negative for characteristic $\mathrm{k}$ between individuals $\mathrm{i}$ and $\mathrm{j}$, and otherwise when the variable is quantitative:

$$
S_{i j}=\frac{\left|Y_{i k}-Y_{j k}\right|}{R_{k}}
$$

with $R_{k}=$ the amplitude of variation of variable $\mathrm{k}$, taking values between 0 and 1 . The value of $W_{i j k}$ was used to define the contributions of the individual's $S_{i j k}$. In this regard, when the value of variable $\mathrm{k}$ was absent in one or both individuals, $W_{i j k}=0$, or otherwise, it was equal to 1 .

The cophenetic correlation coefficient (CCC) was calculated to verify the dendrogram groupings obtained with the UPGMA method. Principal components analysis was used to estimate the contribution of all the characteristics to genetic diversity and the phenotypic correlation among the variables studied. The $t$ test was used at 1 and $5 \%$ probability to test the significance of the correlations. The following software was used to analyze the data: Genes (Cruz, 2006), developed by the Universidade Federal de Viçosa, to obtain the descriptive statistics, principal components analysis and the distance matrix estimates, and the R program - (Project for Statistical Computing, $4 \mathrm{Mega})$ for structure diagrams and the estimation of the cophenetic correlation coefficient.

\section{RESULTS AND DISCUSSION}

One hundred forty-two sibling genotypes, and the two parents were evaluated for fruit and cluster characteristics, and the descriptive statistics for these variables are presented in Table 1. Most of the traits, with the exception of ${ }^{\circ}$ Brix, juice $\mathrm{pH}$ and TP, had high variance, confirming their strong genetic variability. This conclusion was verified by the high coefficients of variation. The test population was a cross between two very different $V$. vinifera cultivars (Riesling and Cabernet Sauvignon), and was expected to create a variable population of progeny and to demonstrate the potential for utilization of genetic variability in grape breeding. 
Table 1. Descriptive statistics for thirteen traits measured from 144 progeny derived from a cross of Riesling $\mathrm{x}$ Cabernet Sauvignon maintained at the National Clonal Germplasm Repository, Winters, CA.

\begin{tabular}{|c|c|c|c|c|c|c|c|c|c|c|c|c|c|}
\hline Trait & $\mathrm{CW}$ & $\mathrm{CL}$ & BW & $\mathrm{BN}$ & $\mathrm{W}$ & WW & WL & $\mathrm{CD}$ & $\mathrm{CN}$ & ${ }^{\circ}$ Brix & $\mathrm{pH}$ & TP & TA \\
\hline Minimum value & 17.40 & 7.00 & 8.54 & 2.00 & 0.00 & 3.60 & 2.00 & 1.00 & 6.00 & 20.73 & 3.46 & 0.20 & 1.80 \\
\hline Maximum value & 352.79 & 26.34 & 46.29 & 98.00 & 1.00 & 130.62 & 21.00 & 9.00 & 50.00 & 32.00 & 5.10 & 2.51 & 4.50 \\
\hline Coefficient of variation & 44.89 & 23.53 & 21.15 & 52.42 & 0.00 & 66.94 & 40.00 & 43.33 & 42.65 & 9.08 & 6.77 & 57.06 & 19.02 \\
\hline Variance & 3421.35 & 11.22 & 38.16 & 295.60 & 0.00 & 40.00 & 10.50 & 4.62 & 118.94 & 5.66 & 0.07 & 0.19 & 2.76 \\
\hline Standard deviation & 58.49 & 3.35 & 6.17 & 17.19 & 0.00 & 52.42 & 3.24 & 2.14 & 10.90 & 2.38 & 0.28 & 0.44 & 0.52 \\
\hline Confidence interval-upper $(95 \%)$ & 139.87 & 14.78 & 30.21 & 36.48 & 1.00 & 97.24 & 8.79 & 5.31 & 27.35 & 26.59 & 4.21 & 0.85 & 2.85 \\
\hline Confidence interval-lower (95\%) & 120.18 & 13.65 & 28.13 & 28.88 & 1.00 & 42.65 & 7.36 & 4.58 & 23.68 & 25.79 & 4.11 & 0.70 & 2.67 \\
\hline General average & 130.29 & 14.23 & 29.20 & 32.79 & 1.00 & 42.54 & 8.10 & 5.36 & 25.57 & 26.20 & 4.16 & 0.77 & 2.76 \\
\hline Riesling mean & 134.01 & 14.11 & 28.59 & 36.00 & 1.00 & 49.99 & 8.50 & 7.00 & 50.00 & 26.71 & 3.70 & 0.27 & 2.77 \\
\hline Cabernet Sauvignon mean & 85.43 & 21.00 & 26.03 & 20.00 & 1.00 & 22.83 & 9.00 & 3.00 & 30.00 & 28.33 & 4.34 & 0.98 & 3.00 \\
\hline
\end{tabular}

The values for all of the variables were found to be within $95 \%$ confidence intervals, verifying the accuracy of the measurements and their utility for the selection of the next generation's parents. A successful breeding program depends on the identification of heterotic genotypes and allelic diversity for traits of interest. It is important to be able to predict which genotypes would best complement each other's alleles, generate improved agronomic performance for select traits, and promote improvement in subsequent generations.

Figure 1 presents the range of genetic diversity in the Riesling x Cabernet Sauvignon population. Estimates of genetic distances were lowest $\left(\mathrm{S}_{\mathrm{ij}}=0.463\right)$ between the Cabernet Sauvignon parent and genotype $\mathrm{G} 77$, and the genetic difference was the greatest $\left(\mathrm{S}_{\mathrm{ij}}=3.804\right)$ between genotypes G27 and G58, demonstrating clear genetic divergence among the progeny and the potential for selection of improved genotypes within this population's set of evaluated traits. In order to discriminate among the groups formed in Figure 1, the following cutoff criterion $=$ mean distances $+\mathrm{KSD}(\mathrm{SD}=$ standard deviation of the distances and $\mathrm{K}=1.25)$ was adopted. Using this criterion, the distances between accessions had an average value of 1.3223 and a standard deviation of 0.6274 . To further cluster the genotypes in the dendrogram, a cutoff value representing $54.82 \%$ of the genetic diversity in the population was chosen, which

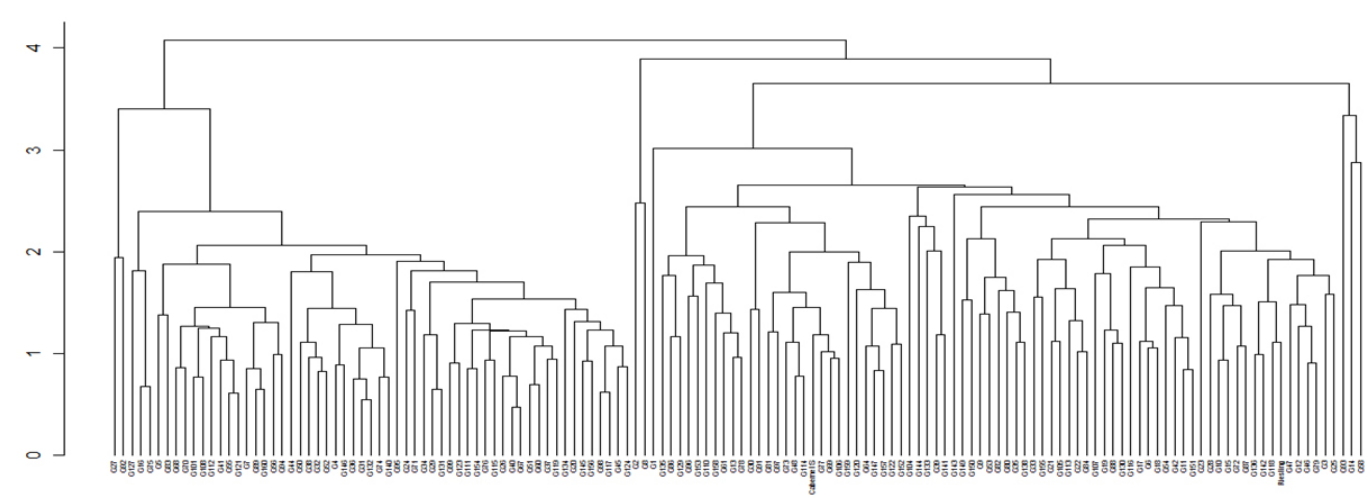

Figure 1. Dendrogram of genetic dissimilarities in a Riesling x Cabernet Sauvignon population of wine grapes, obtained by the UPGMA method and based on 13 evaluated traits using Gower's dissimilarity index. 
corresponded to a value of 2.10 on the y-axis. The dendrogram in Figure 1 was constructed with data from all 13 measured traits. The genotypes were re-evaluated and grouped based on three criteria, which were judged to have high significance for wine grape breeding: average cluster weight, average cluster density and average total phenolics in the skins (Table 2).

\begin{tabular}{|c|c|c|c|c|}
\hline Group & Genotypes & $\begin{array}{l}\text { Avg. cluster } \\
\text { weight }(\mathrm{g})\end{array}$ & $\begin{array}{l}\text { Avg. cluster } \\
\text { density (1-9) }\end{array}$ & $\begin{array}{c}\text { Avg. total } \\
\text { phenolics }(\mathrm{g} / \mathrm{L})\end{array}$ \\
\hline I & $27,92,127,16,75,05,83,60,70,101,108,112,41,55,121$ & 85 & 3 & 0.75 \\
\hline II & $07,89,160,56,94,44,50,38,32,52,04$ & 159 & 3 & 0.68 \\
\hline III & $146,36,31,132,74,140,95,24,71,34,29,131$ & 120 & 3 & 0.56 \\
\hline IV & $99,123,111,154,76,115,26,40,67$ & 97 & 3 & 0.70 \\
\hline $\mathrm{V}$ & $51,60,37,119,134,20,145,156,98,117,45,124$ & 78 & 5 & 0.67 \\
\hline VI & $02,08,01,135,86,129,96,153,110,158,61,13,78,30,91,81,97$ & 108 & 5 & 0.89 \\
\hline VII & $73,48,114$, Cabernet Sauvignon, 77, 69, 106 & 110 & 5 & 1.10 \\
\hline VIII & $159,120,64,147,157,122,152,104,144,133,39,141$ & 120 & 5 & 1.05 \\
\hline IX & $\begin{array}{l}143,149,150,09,53,82,80,35,138,33,155,21,105,113,22,84 \\
\quad 107,19,88,130,116,17,06,18,54,42,11,151\end{array}$ & 190 & 7 & 0.95 \\
\hline $\mathrm{X}$ & $23,28,10,15,72,87,136,142,118$, Riesling, $47,12,46,79,03,25$ & 170 & 7 & 0.85 \\
\hline XI & $93,14,58$ & 228 & 5 & 0.42 \\
\hline
\end{tabular}

Genetic factors have been found to be responsible for variation in the content of phenolic compounds in many crops (Lima et al., 2005; Singleton, 1966). Phenolics have also been shown to play an important role in the quality of grapes. Genetics, climatic differences and cultural practices have all been shown to affect phenolic levels and grape and wine quality (Sinton et al., 1978; Cantos et al., 2002; Iacopini et al., 2008). Groups VII, VIII, IX, and X were unusual because they contained genotypes with relatively large $(>180.0 \mathrm{~g})$ clusters and high levels of total phenolics (Table 2). This observation confirms the potential of this population for the selection of new parental genotypes for use in breeding focused on high-quality and disease-resistant grapevines. The distribution of progeny into groups provides the breeder with an important tool. It facilitates the selection of genetically diverse and superior genotypes from different groups, thereby promoting heterosis since it is a function of genetic distance between parents.

One of the goals of this study was to identify transgressive segregants; individuals in the population that exceeded the parents in their phenotypic expression for given traits. Transgressive segregation is often the product of complementary gene action resulting from the combination of alleles from both parents that have effects in the same directions. Thus, hybrid individuals that combine "plus" alleles from both parents or "minus" alleles from both parents are likely to have more extreme phenotypes (Rieseberg et al., 2003). In this study, Riesling had a total phenolics value of $0.27 \mathrm{~g} / \mathrm{L}$, similar to values observed in other studies (Singleton, 1966). There were several white-fruited progeny in the population with total phenolic values ranging from 0.330 to 0.450 , higher values than that of the white-berried Riesling parent. This finding demonstrates that selection for increased total phenolics would also be possible in white-fruited grape varieties. Only total phenolics were measured in this study; however, the ratio of different phenolic compounds (anthocyanins, flavonoids, hydroxycinnamic acid derivatives, and flavon-3-ols) could be different in each genotype. Cantos et al. (2002) observed that the table grape cultivars Crimson Seedless and Napoleon had the same level of total phenolics as Flame Seedless and Redglobe, but they had lower anthocyanins and higher levels of 
flavon-3-ols. A similar situation could exist in this Riesling x Cabernet Sauvignon population, and future studies should examine specific phenolic compounds. This work could be simplified by targeting specific groups of progeny given the correlational analysis presented here.

The cophenetic correlation coefficient was 0.72 , confirming that the groupings were accurate (Sokal and Rohlf, 1962), and the UPGMA distance metrics also validated the groupings. The population data was also used to estimate phenotypic correlations between traits, which are presented in Table 3. The important variable total cluster weight was positively correlated with cluster length $\left(0.646^{* *}\right)$, berry weight $\left(0.513^{* *}\right)$, the presence of a wing $\left(0.217^{* *}\right)$, wing weight $\left(0.506^{* *}\right)$ and length $\left(0.385^{* *}\right)$, berry number $\left(0.415^{* *}\right)$, cluster density $(0.242 * *)$, and the number of clusters $(0.362 * *)$. However, total cluster weight was negatively correlated with $\mathrm{pH}\left(-0.238^{* *}\right)$ and total phenolics $\left(-0.319^{* *}\right)$, indicating that selection of genotypes with higher cluster weights should be done with careful consideration of fruit quality traits. There was also a negative correlation between estimates of berry weight, presence of a wing, wing weight and number of clusters to the juice $\mathrm{pH}$ and total phenolics (Table 3 ). In order to select more effectively among these traits, multivariate selection indices can be used for variables that are negatively correlated. These indices assign an arbitrary weight to the most important variables under selection, allowing genetic gain for multiple characteristics, and they have been used successfully in other species of agronomic interest (Granate et al., 2002; Santos et al., 2008). Strong and positive correlations of variables associated with complex traits can be very valuable for crop improvement. For example, the number of berries was the most important trait in the determination of cluster weight and total yield. The positive correlation observed in this study between number of clusters and number of berries is a significant help to grape breeders, as the easily counted clusters will also result in progeny with greater berry number and cluster weights.

Table 3. Estimates of phenotypic $\left(r_{f}\right)$ correlation, among 13 traits evaluated in a Riesling x Cabernet Sauvignon seedling population growing at the National Clonal Germplasm Repository, Winters, CA. See Table 1 for definitions of trait abbreviations.

\begin{tabular}{|c|c|c|c|c|c|c|c|c|c|c|c|c|c|}
\hline Traits & $\mathrm{CW}$ & LC & BW & Wing & WW & WL & $\mathrm{BN}$ & $\mathrm{CD}$ & $\mathrm{NC}$ & ${ }^{\circ}$ Brix & $\mathrm{Ph}$ & TP & TA \\
\hline TCW & & $0.646^{* *}$ & $0.513 * *$ & $0.217^{* *}$ & $0.506^{* *}$ & $0.385 * *$ & $0.415^{* *}$ & $0.242 * *$ & $0.362^{* * *}$ & -0.111 & $-0.238^{* *}$ & $-0.319^{* *}$ & 0.067 \\
\hline $\mathrm{LC}$ & & & $0.281 * *$ & $0.199 *$ & $0.337^{*}$ & $0.401 * *$ & $0.302 * *$ & $0.185^{*}$ & $0.265^{* *}$ & 0.063 & -0.082 & $-0.187 *$ & 0.097 \\
\hline BW & & & & 0.060 & $0.188^{*}$ & 0.100 & 0.047 & $0.166^{*}$ & 0.085 & $-0.304 * *$ & $-0.179 *$ & $-0.281 * *$ & -0.021 \\
\hline Wing & & & & & $0.686^{* *}$ & $0.839 * *$ & $0.767^{* *}$ & 0.094 & 0.076 & -0.091 & -0.154 & -0.149 & 0.110 \\
\hline WW & & & & & & $0.858^{* *}$ & $0.939^{* *}$ & 0.125 & 0.128 & -0.068 & $-0.205^{*}$ & $-0.196 *$ & 0.137 \\
\hline WL & & & & & & & $0.888^{* *}$ & $0.194 *$ & 0.148 & -0.041 & -0.097 & -0.143 & 0.096 \\
\hline $\mathrm{BN}$ & & & & & & & & 0.088 & 0.125 & -0.006 & -0.096 & -0.158 & 0.106 \\
\hline $\mathrm{CD}$ & & & & & & & & & 0.136 & -0.144 & -0.013 & -0.111 & 0.041 \\
\hline $\mathrm{NC}$ & & & & & & & & & & $0.252 * *$ & -0.880 ** & -0.121 & 0.030 \\
\hline${ }^{\circ}$ Brix & & & & & & & & & & & 0.138 & $0.180^{*}$ & 0.060 \\
\hline $\mathrm{Ph}$ & & & & & & & & & & & & $0.208^{*}$ & $-0.425 * *$ \\
\hline $\mathrm{TP}$ & & & & & & & & & & & & & -0.058 \\
\hline $\mathrm{TA}$ & & & & & & & & & & & & & \\
\hline
\end{tabular}

****Significantly different from zero at 5 and $1 \%$ probability levels for a $t$-test, respectively.

In order to study the relative contribution of each trait, Cruz and Carneiro (2003) suggest considering the weighting of eigenvalues. Traits with larger weightings have reduced variance associated with them and therefore more emphasis should be placed on eigenvalues with coefficients smaller than 0.7. Given this relationship, Table 4 presents the recorded features in order of their eigenvector values. The highest values in the last eigenvectors were for number 
of clusters, total phenolics and presence/absence of a cluster wing, indicating that these traits have limited value for selection in the population. However, total phenolics cannot be discarded given their importance in fruit quality. The traits wing length, total cluster weight, cluster density, wing weight, berry weight, $\mathrm{pH}$, and titratable acidity had good discriminating power in this population, which is further enhanced by the importance of these traits for wine grape quality. This study found that abundant genetic diversity existed in a cross between two different wine grapes varieties. Thirteen traits were examined and clear genetic diversity among genotypes was observed. This study showed that diversity allows breeding progress to be expedited by selection of new individuals with superior characteristics for use as parents in the development of new wine grapes. All thirteen of the traits under evaluation were useful in the discrimination of genetic diversity in this population. However, the traits that had the greatest influence on the estimation of genetic diversity were wing length, number of berries, cluster density and peduncle length. The strongest association between a trait and crop yield, and thus the trait with the greatest predictive value was the number of berries.

Table 4. Variance estimates (eigenvalues) of principal components (PC) and respective associated vectors (eigenvectors) for the 13 traits evaluated in a Riesling $\mathrm{x}$ Cabernet Sauvignon seedling population growing at the National Clonal Germplasm Repository, Winters, CA. See Table 1 for definitions of trait abbreviations.

\begin{tabular}{|c|c|c|c|c|c|c|c|c|c|c|c|c|c|c|c|}
\hline \multirow[b]{2}{*}{$\mathrm{PC}$} & \multirow[b]{2}{*}{$\begin{array}{c}\text { Variance } \\
\text { (eigenvalues) }\end{array}$} & \multirow[b]{2}{*}{$\begin{array}{c}\text { Accumulated } \\
\text { variance }(\%)\end{array}$} & \multicolumn{13}{|c|}{ Weighted coefficient associated with traits evaluated } \\
\hline & & & TCW & $\mathrm{LC}$ & BW & Wing & WW & WL & NB & $\mathrm{CD}$ & $\mathrm{NC}$ & ${ }^{\circ}$ Brix & $\mathrm{Ph}$ & $\mathrm{TP}$ & TA \\
\hline $\mathrm{PC} 1$ & 4.275 & 32.887 & 0.687 & 0.572 & 0.339 & 0.761 & 899 & 0.889 & 0.873 & 0.266 & 0.300 & -0.113 & -0.288 & -0.347 & 0.195 \\
\hline PC2 & 1.882 & 368 & 0.521 & 0.377 & 0.644 & -0.424 & -0.257 & -0.359 & -0.408 & 0.292 & 0.297 & -0.267 & -0.292 & -0.419 & 0.058 \\
\hline PC3 & 1.457 & 58.581 & 0.172 & 0.423 & -0.226 & -0.158 & -0.072 & -0.004 & -0.014 & 0.009 & 0.660 & 0.742 & 0.334 & 0.219 & -0.135 \\
\hline PC4 & 1.342 & 68.909 & 0.083 & 0.037 & 0.230 & 0.014 & 0.020 & 0.087 & 0.046 & 0.210 & -0.134 & -0.300 & 0.674 & 0.004 & -0.813 \\
\hline PC5 & 0.924 & 76.019 & -0.103 & -0.028 & -0.168 & 0.015 & -0.062 & 0.061 & -0.053 & 0.859 & 0.003 & -0.084 & 0.048 & 0.262 & 0.237 \\
\hline PC6 & 0.786 & 82.070 & 0.186 & 0.236 & 0.261 & -0.094 & 0.054 & 0.004 & -0.010 & -0.169 & -0.233 & -0.084 & -0.023 & 0.715 & 0.114 \\
\hline PC7 & 0.630 & 86.921 & -0.050 & -0.295 & 0.049 & 0.117 & 0.007 & -0.001 & -0.013 & -0.011 & 0.471 & -0.182 & -0.331 & 0.272 & -0.290 \\
\hline PC8 & 0.528 & 90.985 & 0.021 & 0.334 & -0.435 & -0.007 & -0.088 & 0.013 & -0.034 & -0.128 & 0.105 & -0.435 & 0.012 & -0.001 & 0.011 \\
\hline PC9 & 0.466 & 94.571 & 0.142 & 0.088 & -0.226 & -0.133 & 0.069 & -0.028 & 0.023 & 0.119 & -0.268 & 0.167 & -0.366 & -0.003 & -0.338 \\
\hline PC10 & 0.389 & 97.569 & -0.243 & 0.257 & 0.131 & 0.332 & -0.237 & 0.111 & -0.178 & 0.007 & -0.064 & 0.091 & -0.120 & -0.008 & -0.097 \\
\hline PC11 & 0.204 & 99.145 & 0.300 & -0.123 & -0.083 & 0.232 & -0.154 & -0.061 & -0.063 & -0.011 & -0.047 & 0.028 & 0.046 & 0.018 & 0.024 \\
\hline $\mathrm{PC} 12$ & 0.074 & 99.716 & 0.041 & -0.053 & -0.009 & -0.084 & -0.046 & 0.223 & -0.098 & -0.021 & -0.002 & 0.001 & -0.002 & -0.007 & 0.006 \\
\hline $\mathrm{PC} 13$ & 0.036 & 100.00 & -0.001 & -0.003 & 0.016 & -0.035 & -0.128 & 0.019 & 0.134 & 0.001 & -0.001 & -0.003 & -0.015 & 0.001 & -0.002 \\
\hline
\end{tabular}

\section{ACKNOWLEDGMENTS}

A.P. Viana thanks the National Council for Scientific and Technological Development (CNPq) for a fellowship that allowed training in the Department of Viticulture and Enology, University of California at Davis.

\section{REFERENCES}

Amerine MA and Ough CS (1980). Methods for Analysis of Musts and Wines. Wiley and Sons, New York.

Cantos E, Espin JC and Tomas-Barberan FA (2002). Varietal differences among the polyphenol profiles of seven table grape cultivars studied by LC-DAD-MS-MS. J. Agric. Food Chem. 50: 5691-5696.

Cruz CD (2006). Programa Genes (Versão Windows), Aplicativo Computacional em Genética e Estatística. Editora UFV, Viçosa.

Cruz CD and Carneiro PCS (2003). Modelos Biométricos Aplicados ao Melhoramento Genético. Editora UFV, Viçosa. deVicente MC and Tanksley SD (1993). QTL analysis of transgressive segregation in an interspecific tomato cross. 
Genetics 134: 585-596.

Dokoozlian NK and Kliewer WM (1996). Influence of light on grape berry growth and composition varies during fruit development. J. Amer. Soc. Hort. Sci. 121: 869-874.

Falconer DS and Mackay TFC (1996). Introduction to Quantitative Genetics. 4th edn. Longman, London.

Gower JC (1971). A general coefficient of similarity and some of its properties. Biometrics 27: 857-871.

Granate MJ, Cruz CD and Pacheco CAP (2002). Predição de ganho genético com diferentes índices de seleção no milho pipoca CMS-43. Pesq. Agropec. Bras. Brasília 37: 1001-1008.

Grant V (1975). Genetics of Flowering Plants. 2nd edn. Columbia University Press, New York.

Iacopini P, Baldi M, Storchi P and Sebastiani L (2008). Catechin, epicatechin, quercetin, rutin and resveratrol in red grape: Content, in vitro antioxidant activity and interactions. J. Food Comp. Anal. 21: 589-598.

IPGRI, UPOV and OIV (1997). Descriptors for Grapevine (Vitis spp.). International Union for the Protection of New Varieties of Plants, Geneva, Switzerland/Office International de la Vigne et du Vin. International Plant Genetic Resources Institute, Paris.

Lima LAGV, Mélo EA, Maciel MIS, Prazeres FG, et al. (2005). Total phenolic and carotenoid contents in acerola genotypes harvested at three ripening stages. Food Chem. 90: 565-568.

Marois JJ, Nelson JK, Morrison JC, Lile LS, et al. (1986). The influence of berry contact within grape clusters on the development of Botrytis cinerea and epicuticular wax. Am. J. Enol. Vitic. 37: 293-296.

Marois JJ, Bledsone AM and Bettiga LJ (1992). Bunch rots. Grape Pest Management. Univ. Calif., Div. Agric. Nat Res. Publ. No. 3343.

Michailides TJ (1991). Susceptibility of pistachio male cultivars to Botrytis blossom and shoot blight caused by Botrytis cinerea. Plant Dis. 75: 410-415.

Rieseberg LH and Ellstrand NC (1993). What can molecular and morphological markers tell us about plant hybridization? Crit. Rev. Plant Sci. 12: 213-241.

Rieseberg LH, Widmer A, Arntz AM and Burke JM (2003). The genetic architecture necessary for transgressive segregation is common in both natural and domesticated populations. Phil. Trans. Roy. Soc. London B 358: 1141-1147.

Santos FS, Amaral AT Jr, Freitas SP Jr, Rangel RM, et al. (2008). Genetic gain prediction of the third recurrent selection cycle in a popcorn population. Acta Sci. Agron. 30: 651-655.

Singleton VL (1966). The total phenolic content of grape berries during the maturation of several varieties. Am. J. Enol. Vitic. 17: 126-134.

Sinton TH, Ough CS, Kissler JJ and Kasimatis AN (1978). Grape juice indicators for prediction of potential wine quality. I. Relationship between crop level, juice and wine composition, and wine sensory ratings and scores. Am. J. Enol. Vitic. 29: 267-271.

Sokal RR and Rohlf FJ (1962). The comparison of dendrograms by objective methods. Taxon 11: 33-40.

Thomas CA and Orellana RG (1963). Nature of predisposition of castorbeans to Botrytis. II. Raceme compactness, internode length, position of staminate flowers, and bloom in relation to capsule susceptibility. Phytopathology 53: 249-251.

Vail ME and Marois JJ (1991). Grape cluster architecture and the susceptibility of berries to Botrytis cinerea. Phytopathology 81: 188-191.

Weaver RJ, Kasimatis AN and McCune SB (1962). Studies with gibberellin on wine grapes to decrease bunch rot. Am. J. Enol. Vitic. 13: 78-82. 